Seção Temática: Os Recursos Públicos em Disputa

Volume 11 - $2021 \mid$ n. 32

\title{
Pandemia: janela de oportunidade para a privatização na educação básica do estado de São Paulo
}

\author{
Carolina Barbosa Gomes Figueiredo Filho \\ Universidade Estadual de Campinas (UNICAMP), Campinas/SP - Brasil \\ João Batista Silva dos Santos \\ Universidade de São Paulo (USP), São Paulo/SP - Brasil
}

\section{Resumo}

Este trabalho analisa como o modelo de ensino remoto, implementado em virtude da pandemia, agravou o processo de privatização da Rede Estadual de Ensino do Estado de São Paulo (REE-SP). Para analisar como o ensino remoto acentuou e conferiu novos contornos a esse fenômeno, utilizaram-se dados de contratos e termos de cooperação firmados pela Secretaria de Educação (SEDUC) em meio à pandemia e acessados via Serviço de Informação ao Consumidor (SIC) ou disponibilizados nos veículos oficiais do governo estadual. Verifica-se que o momento se consolidou como uma "janela de oportunidades" para fundações, empresas e institutos privados difundirem seus serviços e produtos por dentro da escola pública.

Palavras-chave: Educação Básica. Privatização. Ensino Remoto.

\section{Pandemic: window of opportunity for privatization in basic education in the state of São Paulo}

\begin{abstract}
This paper intends to analyze how the model of remote education, implemented due to the pandemic period, increased the privatization process process of the São Paulo State Education Network (REE-SP). To analyze how remote learning accentuated and gave new contours to this phenomenon, data from contracts and terms of cooperation signed by the Department of Education (SEDUC) were used in the midst of the pandemic and accessed via the Consumer Information Service (SIC) or made available on official state government vehicles. It appears that the moment has consolidated itself as a "window of opportunity" for foundations, companies, and private institutes to disseminate their services and products within the public school.
\end{abstract}

Keywords: Basic Education. Privatization. Remote Teaching. 


\section{Escola Pública Paulista: complexidade, precariedade e tendência privatista}

O estado paulista se consagrou como expoente do ideário neoliberal da Nova Gestão Pública no país a partir dos anos 1990, por meio de sistemáticas reformas do Estado, enxugamento dos serviços públicos, privatização, abertura comercial e financeira, ajustes fiscais, flexibilização de direitos sociais e trabalhistas. Na mesma toada, as políticas que visam maior "racionalização" e "eficiência" na educação acompanham os governos estaduais do PSDB em São Paulo desde seu início, em 1995, a exemplo da reorganização escolar do governo de Mário Covas (1995-2001), assim como das sucessivas reformulações curriculares, adoção de materiais didáticos padronizados, foco nos índices de resultado das avaliações externas, maior número de alunos por sala de aula, bonificação salarial e quantidade expressiva de contratos temporários de professores que marcaram os governos de Geraldo Alckmin (2001-2006; 2011-2018) e de José Serra (2007-2010) (ADRIÃO; GARCIA; DRABACH, 2020; CARVALHO; RUSSO, 2014; FERNANDES; BARBOSA; VENCO, 2019; FREITAS, 2018; GOULART; PINTO; CAMARGO, 2017; VENCO, 2016a; 2016b).

O estado de São Paulo é a unidade federativa de maior importância em termos econômico, político e social. Segundo dados do IBGE de 2020, o PIB per capita do estado fica em segundo lugar do Brasil, alcançando o valor de aproximadamente $\mathrm{R} \$ 52.159,29$ para uma população de mais de 46 milhões de habitantes. Se compararmos com a população brasileira, calculada em 211.755.692 habitantes, para o mesmo ano, São Paulo representava aproximadamente $22 \%$ de toda a população do País (IBGE, 2020).

Esse cenário impacta na constituição da Rede Estadual de Ensino do Estado de São Paulo (REE-SP). De acordo com o Laboratório de Dados Educacionais (LDE) da Universidade Federal do Paraná (UFPR) ${ }^{1}$, em 2019, a educação básica no estado de São Paulo alcançou o número de 10.018.115 matrículas, distribuídas nas dependências administrativas Federal, Estadual, Municipal e Privada. Destas, 3.656.265 são relativas apenas ao âmbito Estadual, ou seja, destinam-se à REE-SP, número que representa mais de $35 \%$ do total. Para atender ao volumoso número de matrículas, 5.681 unidades escolares compunham essa rede.

Em termos do quadro de trabalhadores da educação existiam, em 2019, um total de 208.765 profissionais na REE-SP, distribuídos entre 59.390 funcionários não docentes, ou seja, atuantes fora da sala de aula, como secretários de escolas, agentes de organização escolar, supervisores, entre outros, e 149.375 professores. Além do número de professores insuficiente para atender uma demanda de tal monta, tem ocorrido diminuição drástica entre os funcionários não docentes, que sofreram uma redução de $60,8 \%$ de 2017 a 2019 . O número de professores também foi reduzido, ainda que progressivamente: de 2012 a 2019 diminuiu 18\%. De acordo com Venco (2016b), uma das consequências diretas da diminuição de professores é a superlotação em sala de aula, que se evidencia como política do governo estadual, exemplificada pela implementação de medidas que normatizam o aumento do número de alunos por sala de aula, como a Resolução SE n 2, de 8-1-2016, que estabelece diretrizes e critérios para a formação de classes de alunos nas unidades escolares da rede estadual de ensino. De acordo com tal resolução, a SEDUC amplia o número de alunos

1 Todos os dados sobre número de matrículas, de escolas, de funcionários foram coletados junto ao LDE (2020). 
máximo por sala de aula alcançando 30 alunos, para as classes dos anos iniciais do ensino fundamental; 35 alunos, para as classes dos anos/séries finais do ensino fundamental; 40 alunos, para as classes de ensino médio; e 45 alunos, para as turmas de educação de jovens e adultos, nos níveis fundamental e médio. Essa política acentua a precarização da qualidade do ensino.

Ao longo do tempo, o processo de privatização na educação adquiriu diversos modos de manifestação para além da venda do patrimônio público, da expansão de estabelecimentos particulares e do aumento de matrículas nas redes privadas (ADRIÃO; GARCIA; DRABACH, 2020, 2020; BALL; OLMEDO, 2013; CATINI, 2018). Por sua magnitude, a REE-SP, a maior rede de ensino público do Brasil, apresenta-se como um cobiçado espaço para a inserção das corporações privadas. De acordo com Adrião e Garcia (2014), em 2011, o Programa Educação-Compromisso de São Paulo promoveu uma série de "parcerias" público-privadas que deram a tônica para o conjunto das políticas educacionais paulistas da década. $O$ Programa de Ensino Integral (PEI), iniciado em 2012, é um desdobramento do programa anterior, foi formulado em conjunto com entes privados e carrega um modelo empresarial de gestão, organização e avaliação da escola (GIROTTO; JACOMINI, 2019). A proposta de reorganização escolar de 2015 e a implantação do programa Método de Melhoria de Resultados (MMR), a partir de 2016, fruto de "parceria" com a iniciativa privada, também se inserem nesse processo (CÁSSIO et al., 2020; GOULART; PINTO; CAMARGO, 2017). É evidente a progressiva ampliação do papel dos agentes privados junto à elaboração e execução de políticas educacionais em São Paulo, mantida e aprofundada ainda mais pelo governo de João Doria (2019-2022), como confirma a ampla gama de corporações que participaram do Movimento Inova Educação (GOULART; ALENCAR, 2021).

Em relação a essa tendência, o estado de calamidade pública, reconhecido em âmbito federal e estadual devido à pandemia de COVID-19 que acomete o Brasil desde março de 2020, resultou em ações imediatistas da SEDUC com vistas a buscar garantir uma infraestrutura informacional para a continuidade do ano letivo de forma remota (BRASIL, 2020; SÃO PAULO, 2020a; 2020d).

Tais ações, que avaliamos serem necessárias muito antes de uma pandemia avançar contra a comunidade escolar, garantiram muito mais uma "janela de oportunidades" para a entrada de mais setores privados na educação pública do que efetivamente o estabelecimento de uma política sólida de inclusão digital de uma rede tão complexa (SOUZA; EVANGELISTA, 2020).

O chamado "ensino remoto"2, como a própria SEDUC o denomina, implementado de forma improvisada desde abril de 2020 na REE-SP acentua processos e tendências que já estavam em curso nas políticas educacionais do estado, em especial, a privatização da educação, levando-os a uma escala de grande magnitude. Sob a justificativa de que a rede de ensino precisa se adequar ao chamado "novo normal", a SEDUC fomenta a abertura abrupta da educação básica a grandes empresas de telefonia e de tecnologia digital, aos conglomerados que vendem serviços de plataformas virtuais e aplicativos, a fundações e

2 Neste artigo utilizaremos o termo ensino remoto (sem aspas) quando tratarmos do modelo imposto pela SEDUC à rede de ensino estadual de São Paulo. O ensino remoto diverge do ensino a distância em suas concepções didático-pedagógicas e não deve ser confundido. Ver Behar (2020). 
institutos vinculados ao "negócio educacional" como único caminho possível para a escola pública diante do contexto da crise sanitária.

A SEDUC, no intuito de viabilizar o modelo proposto, orientou os professores e estudantes da rede pública de todo o estado a baixar em seus smartphones pessoais um aplicativo chamado Centro de Mídias da Educação de São Paulo (CMSP), desenvolvido pela empresa IP.TV, por meio do qual são transmitidas as videoaulas. O app pode ser acessado por meio de login e senha institucionais. Para conectá-lo, a SEDUC realizou contratos de compra de dados móveis com empresas de telecomunicações. As aulas também são transmitidas pela televisão, em parceria com a Fundação Padre Anchieta (SÃO PAULO, 2020g).

Devido às limitações do aplicativo, no entanto, a própria Secretaria incentivou que as escolas utilizassem outros recursos para interagir com os alunos ou realizar reuniões entre os docentes, como o Google Classroom, Google Meet, Zoom, Microsoft Teams ou até contas pessoais de WhatsApp e Facebook, e também plataformas educacionais privadas, como Dragon Learn, Matific, Descomplica, Explicaê, Joca, Stoodi e outras, com as quais celebrou acordos de cooperação. O uso desses outros meios, contudo, não se dá através dos dados móveis subsidiados pelo estado (SÃO PAULO, 2020c).

Além do CMSP, os alunos em condição de extrema pobreza, cujos responsáveis estão inscritos no Cadastro Único (CadÚnico) ${ }^{3}$ ou são beneficiários do Bolsa Família, precisam baixar um outro aplicativo, o Pic Pay, para poder se cadastrar no programa Merenda em Casa e receber o auxílio de $\mathrm{R} \$ 55$ mensais (BRASIL, 2004; 2007). O acesso a esse aplicativo também demanda um smartphone pessoal e não usufrui dos dados móveis subsidiados.

O ensino remoto em massa é apresentado pelos gestores públicos do estado como saída inevitável para viabilizar que "o calendário escolar não pare" frente à pandemia, mas também como estratégia desejável e "inovadora", "alinhada às demandas do século XXI", que traz consigo uma "oportunidade de reinvenção e de atualização" para a escola pública, como se o uso de recursos tecnológicos por si só garantisse a efetivação em larga escala do complexo processo de ensino-aprendizagem (SÃO PAULO, 2020c). Cabe destacar que não foi garantida a infraestrutura técnica das escolas, aos professores, estudantes e famílias, nem preparação do corpo docente e gestor diante desse modelo, abrindo espaço para o agravamento das desigualdades na educação.

Para melhor compreender e analisar como o modelo de ensino remoto aprofundou a privatização da educação básica paulista, utilizaram-se dados de contratos e termos de cooperação firmados pela SEDUC em meio à pandemia, acessados via Serviço de Informação ao Consumidor (SIC) ou disponibilizados nos veículos oficiais do governo estadual até o mês de setembro de 2020.

3 Base de dados do governo federal que identifica as famílias consideradas de baixa renda para fins de viabilizar o acesso destas a programas sociais. 


\section{Pandemia, Educação e Ensino Remoto como Extensão da Privatização}

A pandemia de COVID-19 acarretou tremendos impactos para a educação. Estima-se que cerca de 1,5 bilhão de crianças e jovens no mundo não puderam frequentar a escola por um longo período no ano de 2020 (UNESCO, 2020). Diante da situação de emergência, diversos empresários e gestores públicos apresentaram a adoção massiva e abrupta do ensino remoto como a "solução" por excelência" ${ }^{4}$. Em um evento promovido em 13 de maio de 2020 pelo Banco BTG Pactual, durante a conferência Brazil at Silicon Valley, as palavras do bilionário brasileiro Jorge Paulo Lemann são emblemáticas sobre os rumos apontados para a educação:

Tivemos uma reunião do conselho da fundação [Lemann] hoje e [...] uma das coisas importantes é o que podemos fazer nessa área de ensino à distância porque essa é a oportunidade grande do momento para ajudar e fazer algo importante para o Brasil no longo prazo (VARGAS, 2020, grifos nossos).

Se, por um lado, a crise agravou desemprego, fome, pobreza, exclusão, por outro, significou uma verdadeira "oportunidade" para alguns setores. A calamidade pública gerada pelo novo coronavírus destacou a educação básica como um "filão" promissor para empresas, institutos e fundações ligados ao negócio educacional ou às tecnologias digitais.

No caso do estado de São Paulo, em pouco mais de 30 dias da decretação do isolamento social (SÃO PAULO, 2020a), a maior rede pública de ensino do País foi tomada por uma maré de serviços, aplicativos e plataformas privados que reconfiguraram as relações pedagógicas e o caráter público da educação. Antes mesmo da paralisação total das aulas presenciais, as primeiras medidas realizadas pelo governo estadual tinham em vista a redução de gastos públicos com a área. Houve suspensão de contratos e convênios relativos à alimentação, ao transporte escolar e ao apoio a alunos com deficiência, logo em 18 de março de 2020 (SÃO PAULO, 2020e). Nos meses que se seguiram, muitos professores temporários e eventuais, os chamados categorias "O" e "V", perderam seus contratos e ficaram sem renda, o que certamente teve impacto na folha de pagamentos ${ }^{5}$. Além disso, as mudanças da reforma da previdência estadual, especialmente o aumento da alíquota de contribuição, passaram a valer durante a pandemia, 90 dias depois de sua sanção em 07 de março. Segundo o governo, pretende-se "economizar R $\$ 58$ bilhões em 15 anos com o pagamento de servidores inativos e pensionistas" (SÃO PAULO, 2020b).

No site Transparência SP, o governo informa que os gastos relacionados ao combate ao coronavírus via Secretaria da Educação somaram, de março até setembro de $2020, \mathrm{R} \$$ 274,94 milhões em valores corrigidos ${ }^{6}$, dos quais $R \$ 256,7$ milhões (93\% do valor total) seriam relativos ao programa Merenda em Casa, advindos do governo federal, referente à quota estadual do salário-educação (SÃO PAULO, 2020i). Cabe destacar que o auxílio no valor de $\mathrm{R} \$ 55$ mensais (menos de $\mathrm{R} \$ 2$ por dia) foi direcionado apenas para 700 mil estudantes (cerca

4 Cabe dizer que essas medidas, em geral, foram tomadas sem instâncias coletivas de debate ou decisão com a comunidade escolar.

5 Solicitamos via Serviço de Informação ao Consumidor (SIC) os dados relativos ao número de contratos temporários rompidos durante a vigência do modelo de ensino remoto em SP, mas não obtivemos resposta com a sistematização desses números.

6 Todos os valores apresentados neste artigo foram corrigidos com base no INPC adotando como mês de referência junho/2021. 
de $20 \%$ do total de discentes) que são beneficiários do Bolsa-Família ou que estão em situação de extrema pobreza.

Os outros gastos descritos no portal do governo, que somaram em torno de $\mathrm{R} \$ 18,57$ milhões, em valores corrigidos, ou $7 \%$ do total, referem-se, parcialmente, a contratos terceirizados de limpeza das escolas e compras de itens de higiene e demais materiais para prevenção do contágio do coronavírus (SÃO PAULO, 2020i). Sobre esses produtos, no entanto, a SEDUC orientou, em informativo de número 3, de 17 de março de 2020, que as próprias unidades escolares deveriam fazer a aquisição utilizando recursos do Programa Dinheiro Direto na Escola (PDDE Paulista), que normalmente é utilizado para os gastos em manutenção e melhoria da aprendizagem, entretanto, pode igualmente ter destinos diversos a depender da decisão da escola ${ }^{7}$ (SÃO PAULO, 2020f).

Outro montante desses gastos é destinado a dois elementos importantes do modelo de ensino remoto: os contratos para acesso móvel à Internet e com a Fundação Padre Anchieta, responsável pelo canal aberto TV Cultura para captação e transmissão de conteúdo audiovisual. A contratação das empresas de telefonia Oi Móvel, Tim, Claro e Telefônica Brasil para subsídio dos dados móveis teve prazo de um ano a partir de abril de 2020 (podendo ser prorrogado em até 60 meses, com reajuste anual), com inexigibilidade de licitação e voltouse exclusivamente para o acesso dos alunos e servidores da rede ao CMSP, num valor total aproximado de mais de $\mathrm{R} \$ 149,6$ milhões/ano, valores corrigidos. Com relação à Fundação Padre Anchieta, o contrato de 6 meses a partir de abril, com dispensa de licitação, foi firmado com valor de $\mathrm{R} \$ 5,54$ milhões para valores corrigidos (Ver Tabela 1).

Tabela 1 - Termos de Contratos firmados pela SEDUC para viabilização do ensino remoto durante a pandemia (até setembro de 2020) via pagamento a empresas

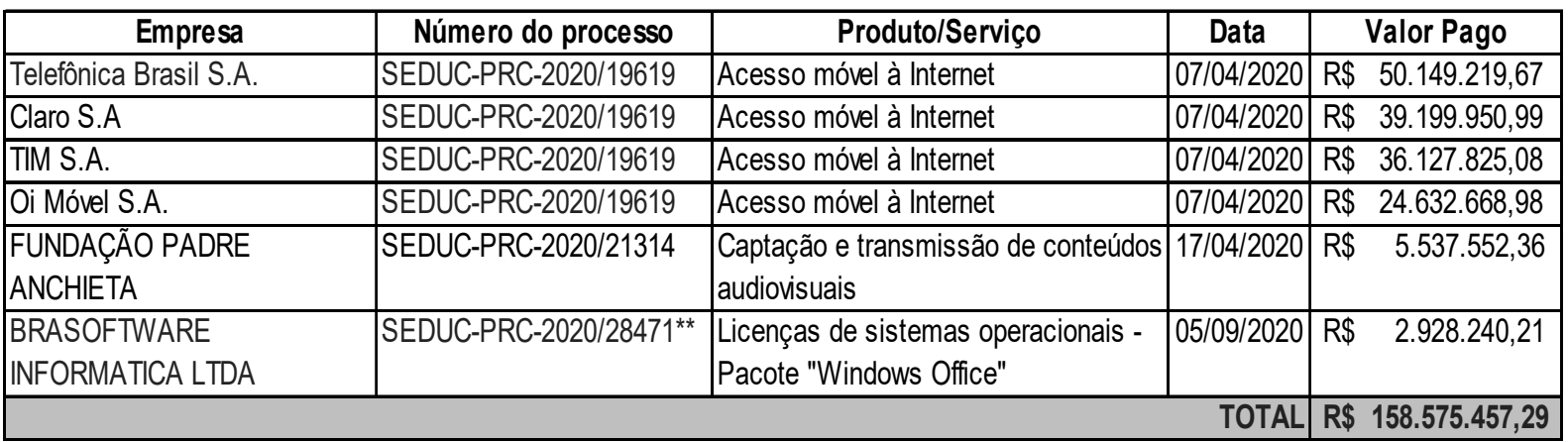

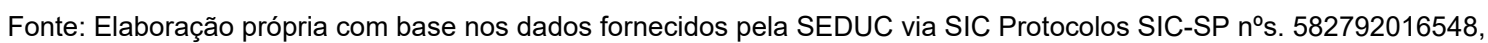
584052016552, 585062016553, 586122016554, 587022016555, 588262016556, 589802016557, 590792016558,

591972016559, 593062016560). Nota: * Contratos com Termo Aditivo; ** Contratos estabelecidos antes do período de pandemia. Valores corrigidos, calculados com referência ao mês de jun. 2021 pelo INPC (IBGE).

Contudo, para além dos gastos publicizados no site, os principais eixos que estruturam o modelo de ensino remoto foram viabilizados com base em uma política deliberada de solicitar "doações" à iniciativa privada. De março até setembro de 2020, a SEDUC realizou nove Chamamentos Públicos para doação de bens e serviços relacionados ao novo contexto. Além disso, em um momento de crise e previsível queda de arrecadação, a Secretaria da

7 "Os recursos do PDDE Paulista [...] também podem, excepcionalmente, ser usados para a aquisição de materiais de higiene que não estejam disponíveis pela Rede de Suprimentos" (SÃO PAULO, 2020d). Na 124a Coletiva de Imprensa, no dia 18 de setembro de 2020, o governo anunciou que repassou em janeiro deste ano $\mathrm{R} \$ 650$ milhões para o PDDE e, devido ao plano de retorno presencial, passará mais R\$50 milhões, para compra de itens essenciais para buscar garantir a reabertura das escolas com condições sanitárias. 
Pandemia

Fazenda e Planejamento elaborou uma cartilha denominada Doações de combate ao coronavírus - como contribuir sem incidência de impostos, orientando pessoas físicas e jurídicas a efetivamente driblar os impostos e oferecer privadamente serviços, produtos e dinheiro aos entes públicos (SÃO PAULO, 2020h).

Desse modo, o próprio site do CMSP cita 16 "parceiros", com o nome e logo de diversas marcas que aderiram aos Chamamentos. Entre as parcerias está o Grupo IP.TV, que presta serviços especializados de tecnologia de informação e foi o responsável pela criação e gestão do aplicativo CMSP, que é a plataforma nuclear do modelo de ensino remoto da REE-SP. O Grupo IP.TV doou seus serviços com um valor estimado de $\mathrm{R} \$ 4,86$ milhões, em valores corrigidos, por 5 meses. Outras marcas divulgadas pelo site oficial que concentra as informações sobre o modelo remoto são de 12 plataformas educacionais privadas, em várias áreas curriculares e voltadas para diferentes níveis de ensino, são elas: Dragon Learn, Guten, Descomplica, Letrus, Mais Educação, Stoodi, Explicaê, Matific, Joca, Imaginie, Mangahigh.com e Acerta Mais ENEM. Em valores corrigidos do estimativo de doação, essas plataformas juntas somam mais de R $\$ 525,3$ milhões. Também são publicizadas parcerias com canais de TV, cursos particulares preparatórios para o vestibular e o Serviço Brasileiro de Apoio às Micro e Pequenas Empresas (SEBRAE).

O aplicativo Pic Pay também doou seus serviços de transação financeira e recebimento de recursos para o poder público estadual, com valor estimado correspondente a mais de $\mathrm{R} \$$ 17,7 milhões, e atua como intermediador do programa Merenda em Casa entre o estado e os responsáveis pelos alunos, recebendo as solicitações do benefício e realizando os pagamentos. Em menor quantidade, o governo recebeu doações de materiais de higiene e prevenção do contágio de empresas variadas, mas não foram exclusivas para a Secretaria de Educação e não foram divulgados os valores estimados desses itens. Os dados de doações foram sistematizados na Tabela 2, em que consta a Razão Social da empresa doadora, o número do processo junto à SEDUC, o produto doado, a data de efetivação e o valor estimado da doação. 
Tabela 2 - Termos de Contratos firmados pela SEDUC para viabilização do ensino remoto durante a pandemia (até setembro de 2020) via doação de empresas

\begin{tabular}{|c|c|c|c|c|}
\hline Empresa & Número do processo & Produto/Serviço & Data & $\begin{array}{l}\text { Valor Doado - } \\
\text { Estimado }\end{array}$ \\
\hline $\begin{array}{l}\text { Stoodi Ensino e Treinamento à Distância } \\
\text { SA }\end{array}$ & $\begin{array}{l}\text { SEDUC- EXP- } \\
2020 / 139771^{*}\end{array}$ & Plataforma Stoodi & $17 / 04 / 2020$ & $\mathrm{R} \$ 136.663 .952,43$ \\
\hline Innyx Tecnologia Ltda & SEDUC-EXP-2020/147403* & Plataforma Explicaê & $15 / 04 / 2020$ & $\mathrm{R} \$ \quad 78.370 .018,61$ \\
\hline Blue Duck Educação Do Brasil Ltda & SEDUC-EXP-2020/154626* & Plataforma Mangahigh.com & $05 / 05 / 2020$ & $\mathrm{R} \$ \quad 67.020 .766,82$ \\
\hline $\begin{array}{l}\text { DESCOMPLICA TECNOLOGIA E } \\
\text { EDUCAÇÃO S.A. }\end{array}$ & SEDUC-EXP-2020/147068* & Plataforma Descomplica & $28 / 04 / 2020$ & $\mathrm{R} \$ \quad 58.979 .847,60$ \\
\hline Escola Mais Educação S/A & SEDUC-EXP-2020/147121 & Plataforma Mais Educação & $24 / 04 / 2020$ & $\begin{array}{ll}\mathrm{R} \$ \quad 58.674 .026,17 \\
\end{array}$ \\
\hline MWC Editora Ltda & SEDUC-EXP-2020/174021 & $\begin{array}{l}\text { Plataformas Acerta Mais ENEM e } \\
\text { Revisa ENEM }\end{array}$ & $12 / 05 / 2020$ & $\mathrm{R} \$ 32.495 .347,52$ \\
\hline SEB Sistema Educacional Brasileiro S.A & SEDUC-EXP-2020/179586 & \begin{tabular}{|l|} 
Bolsas de estudo em curso à \\
distância preparatório para o ENEM
\end{tabular} & $19 / 05 / 2020$ & $\mathrm{R} \$ 21.84$ \\
\hline $\begin{array}{l}\text { FHF VR Servicos de Comunicacao } \\
\text { Multimidia Eireli }\end{array}$ & SEDUC-EXP-2020/147014 & Plataforma Dragon Learn & $14 / 04 / 2020$ & $\mathrm{R} \$ \quad 19.659 .949,20$ \\
\hline PicPay Serviços AS & SEDUC-PRC-2020/19583* & $\begin{array}{l}\text { Transações financeiras e recebimento } \\
\text { de recursos }\end{array}$ & $06 / 04 / 2020$ & $\mathrm{R} \$ \quad 17.693 .954,28$ \\
\hline EDITORA MAGIA DE LER LTDA & SEDUC-EXP-2020/149974* & Jornal Joca & $06 / 05 / 2020$ & $\mathrm{R} \$ \quad 14.450 .062,66$ \\
\hline Matific Brasil Apoio Educacional Ltda & SEDUC-EXP-2020/145334 & Plataforma Matific & $09 / 04 / 2020$ & $\begin{array}{ll}\mathrm{R} \$ & 6.826 .371,25\end{array}$ \\
\hline IP.TV Ltda & SEDUC-EXP-2020/128060* & Aplicativos CMSP & $07 / 04 / 2020$ & $4.860 .376,33$ \\
\hline Amazon Web Services, Inc. (AWS) & & Infraestrutura de servidores e redes & $01 / 04 / 2020$ & $3.713 .545,96$ \\
\hline Imaginie Tecnologia Educacional Ltda & SEDUC-EXP-2020/191999 & Plataforma Imaginie & $12 / 08 / 2020$ & $1.878 .617,37$ \\
\hline $\begin{array}{l}\text { FUNDAÇÃO RÁDIO E TV EDUCATIVA } \\
\text { SEB }\end{array}$ & SEDUC-EXP-2020/190185 & Canal de TV Thathi IN & $29 / 05 / 2020$ & $941.930,01$ \\
\hline $\begin{array}{l}\text { ÁRVORE DE LIVROS, COMÉRCIO, } \\
\text { DISTRIBUIÇÃO E SERVIÇOS S/A }\end{array}$ & SEDUC-EXP-2020/148796 & Plataforma Guten de Leitura & $14 / 04 / 2020$ & $481.445,94$ \\
\hline $\begin{array}{l}\text { CENTRO DE AUTORIA E CULTURA } \\
\text { LTDA }\end{array}$ & SEDUC-EXP-2020/150395* & Plataforma Letrus & $28 / 04 / 2020$ & $471.838,78$ \\
\hline MWC Editora Ltda & SEDUC-EXP-2020/250066 & $\begin{array}{l}\text { Conteúdo de aulas preparatórias para } \\
\text { ENEM }\end{array}$ & $13 / 08 / 2020$ & $294.899,24$ \\
\hline $\begin{array}{l}\text { Serviço de Apoio às Micro e Pequenas } \\
\text { Empresas do Estado de São Paulo - } \\
\text { Sebrae }\end{array}$ & SEDUC-EXP-2020/160249 & $\begin{array}{l}\text { Conteúdos de formação continuada e } \\
\text { empreendedorismo }\end{array}$ & $15 / 05 / 2020$ & 376,82 \\
\hline \multicolumn{4}{|c|}{+2} & $R \$ 525.321 .714,98$ \\
\hline
\end{tabular}

Fonte: Elaboração própria com base nos dados fornecidos pela SEDUC via SIC Protocolos SIC-SP nº. 582792016548, 584052016552, 585062016553, 586122016554, 587022016555, 588262016556, 589802016557, 590792016558, 591972016559, 593062016560 ) ou disponibilizados no site do CMSP. Nota: ${ }^{*}$ Contratos com Termo Aditivo; ${ }^{*}$ Contrato estabelecidos antes do período de pandemia. Valores corrigidos, calculados com referência ao mês de jun. 2021 pelo INPC (IBGE).

Com o intuito de apresentar um panorama das potenciais relações mercadológicas que envolvem as doações realizadas por esse pool de empresas à SEDUC, escolhemos alguns casos para discutir entre aquelas que compreenderam maiores valores estimados de doação.

No primeiro caso, a empresa Stoodi Ensino e Treinamento à Distância SA é um sintoma muito evidente das complexas relações do mercado educacional. Sua doação para a SEDUC alcançou a cifra superior a 136,7 milhões de reais, sendo a maior quantia estimada doada para a Secretaria de acordo com os dados da Tabela 2.

A "startup brasileira de educação", criada em 2013, como o próprio nome da empresa salienta, desenvolve uma plataforma de conteúdos voltados para estudantes que pretendem prestar os vestibulares/ENEM (STOODI..., 2020). Quatro anos após sua criação, em 2017, a empresa foi comprada pelo grupo Somos Educação por aproximadamente 15 milhões de reais, um valor muito pequeno perto dos ativos de seu comprador (SAMOR, 2017). Um ano após esse pequeno negócio, a empresa Kroton Educacional, maior empresa do ramo de educação superior privada no Brasil, compra a Somos Educação pela cifra de 4,5 bilhões de reais. De acordo com Galzerano (2016), a empresa Somos Educação já apresentava um 
controle considerável no mercado editorial brasileiro, possuindo editoras de peso como Ática, Scipione e Saraiva. Sob seu guarda-chuva, há a posse de diversas empresas, que somam 19 marcas ao todo, entre editoras, colégios particulares, sistemas de ensino, etc.

Com essa compra, a Kroton Educacional deu mais um passo no que chama de "mercado de ensino", após o Conselho Administrativo de Defesa Econômica (CADE) vetar a tentativa de unificação entre as duas maiores instituições privadas de ensino superior do Brasil, por considerar que tamanha concentração ofereceria riscos à concorrência (BRASIL; CADE, 2017).

Após o veto, a maior empresa de educação privada no País focou a educação básica com grandes objetivos de crescimento. A prova é sua reorganização estratégica realizada no início de outubro de 2019, quando a empresa anunciou a criação de uma holding com quatro subsidiárias e uma empresa de investimento em startups. As quatro subsidiárias focaram seus objetivos mercadológicos tanto na educação superior quanto na educação básica, distribuindo-se em: Kroton (Ensino superior); Platos (Prestação de serviços às instituições do ensino superior); Saber (Ensino na educação básica) e Somos Educação e Vasta Educação (Prestação de serviços às instituições da educação básica); além da Cogna Venture Capital (investidora em startups) (FEPESP, 2019; SEKI, 2020).

O segundo exemplo dos "novos filantropos", conforme definem Ball e Olmedo (2013), é a empresa Escola Mais Educação SA, com a doação considerável de mais de 58,7 milhões de reais pela disponibilidade da Plataforma Mais Educação. A Plataforma fornecida pela Escola Mais Educação, em sua frente denominada Escola Mais Digital, fornece proposta de estudos que, de acordo com o site da SEDUC, "[...] os alunos estudam de forma autônoma e realizam exercícios por meio dos conteúdos disponibilizados na plataforma" (SÃO PAULO, 2020d).

Quando verificamos os vínculos da Escola Mais compreendemos melhor os motivos de sua "benevolente" doação. A Escola Mais Educação faz parte desde 2017 do Grupo Bahema Educação, um grupo que atua desde a década de 1950, mas só a partir dos anos 2000 resolveu "analisar oportunidades de investimentos em Educação Básica" (BAHEMA, 2020). De acordo com o próprio site do grupo empresarial, que no século passado se dedicava ao mercado de máquinas agrícolas, o ramo de educação básica seria a oportunidade de ampliar os investimentos. De fato, o que ocorria conforme um de seus sócios era: "A empresa estava para ser fechada e tinha uma reserva de $R \$ 30$ milhões, que foi repassada ao projeto de educação depois do plano de negócios ser aprovado pelo conselho da família em 2015" (BLANCO; VAZ, 2019).

Com essa ideia o grupo comprou um pool de escolas construtivistas de elite em São Paulo/SP, Belo Horizonte/MG, Florianópolis/SC, entretanto, adquiriu também escolas que são consideradas de baixo custo, a exemplo da Escola Mais Educação. O sócio relata seu objetivo: "Se conseguirmos chegar a um modelo de escola com valor abaixo do que é pago pelo governo por criança, pode ocorrer uma transferência de valores e ser um caminho para ajudar a melhorar as escolas no Brasil" (BLANCO; VAZ, 2019). Aparentemente, o know-how de sua formação em administração e a experiência no mercado financeiro não levaram em consideração os estudos da Associação Nacional de Pesquisa em Financiamento da Educação (FINEDUCA, 2020), que em sua Nota Técnica, com data de julho de 2020, aponta o valor do Fundeb, no agregado nacional, limitando-se aos R 492,00 por mês. Isto é, a 
apresentação de um discurso, por parte das instituições privadas, de que é possível baixar o custo por aluno a um valor menor do que o governo efetua, com a falsa ideia de oferecer qualidade educacional, caracteriza-se, quando observada a realidade do financiamento da educação no Brasil, como um verdadeiro embuste.

O terceiro exemplo é a empresa Blue Duck Educação do Brasil LTDA, uma desenvolvedora de software educacional com sede em Londres, Reino Unido ${ }^{8}$. Na tabela citada, a empresa aparece como responsável por uma "doação" superior a $\mathrm{R} \$ 67,02$ milhões de reais. A empresa, que desenvolveu um software de aprendizagem matemática chamado Mangahigh, foi adquirida pelo grupo internacional Westermann Gruppe em fevereiro de 2018. Tal organização, por sua vez, consiste numa grande empresa alemã voltada para o ramo da mídia educacional e, como o próprio site da empresa noticiou, seus anseios são para além de "ambiciosos".

A Westermann Gruppe está expandindo seu portfólio com Mangahigh.com para oferecer mais oportunidades de aprendizagem lúdica e digital. Essa aquisição também deve abrir caminho para uma rápida expansão em novos mercados. 'Estamos muito satisfeitos, juntamente com nossa nova empresa ambiciosa para fortalecer nossa presença nos mercados internacionais', disse Ralf Halfbrodt, CEO da Westermann Gruppe (WESTERMANN GRUPPE, 2018, tradução livre, grifos nossos).

A ideia de mercado é explicitamente muito mais presente do que a ideia de qualidade de ensino e aprendizagem.

Há, ainda, três grandes "parceiros" de peso que foram mobilizados para a dinâmica do ensino remoto: as gigantes multinacionais da tecnologia digital, Amazon, Google e Microsoft. No caso da Amazon, seus serviços doados se referem a créditos promocionais associados à infraestrutura de computadores e redes do setor de "nuvem" da Amazon Web Services (AWS), estimados em pouco mais de R $\$ 3,71$ milhões (SÃO PAULO, 2020d).

A relação da SEDUC com a Google e com a Microsoft é anterior à pandemia. Há alguns anos, todos os professores da rede possuem dois endereços eletrônicos institucionais: um da Google, que dá acesso ao conjunto de serviços e plataformas da empresa, como o Google Meet, Hangout, Google Drive, Google Classroom etc, e outro da Microsoft, que é estendido também aos alunos, e que oferece o pacote Office, inclusive o programa de reuniões e videoconferências Microsoft Teams para os docentes (SÃO PAULO, 2013). Desde 2014, a Secretaria afirma celebrar convênio sem ônus financeiro com a Google para disponibilização das plataformas e serviços ligados ao Google for Education. No documento que formaliza a parceria, o tamanho da rede de ensino do estado é ressaltado como uma vantagem para o estabelecimento do contrato, além de expressar os objetivos da Google em "Difundir o uso institucionalizado dos aplicativos da Google entre os professores" (SÃO PAULO; GOOGLE, 2014, p. 4) e gestores da educação básica, propondo, inclusive, metas de capacitação dos docentes. Mais uma vez, os serviços e produtos privados são apresentados como única "solução" viável e possível para atender a determinadas demandas da rede educacional. Em relação à Microsoft, o acordo não é de doação e o uso das licenças da empresa foi mediado pela Brasoftware Informática, listada na Tabela 1. Em 5 de setembro de 2020, foi firmado contrato de renovação da licença para uso dos sistemas operacionais da empresa, licitado

8 Emissão de Comprovante de Inscrição e de Situação Cadastral da Receita Federal. http://servicos.receita.fazenda.gov.br/Servicos/cnpjreva/Cnpjreva_Solicitacao.asp?cnpj=. Acesso em: 01 ago. 2020. 
por meio de Pregão Eletrônico, com o valor corrigido de $\mathrm{R} \$ 2,93$ milhões $^{9}$. Ainda que ambas as parcerias tenham se iniciado em anos anteriores, é inegável que a utilização dos produtos Google e Microsoft por estudantes e docentes se amplificou sobremaneira em meio à pandemia e que esses recursos também se consolidaram como pilares do ensino remoto, com destaque para reuniões obrigatórias da jornada docente de Aula de Trabalho Pedagógico Coletivo (ATPC) via Microsoft Teams e para o aplicativo Google Classroom, que após alguns meses foi vinculado diretamente ao próprio CMSP.

De acordo com o levantamento das doações à SEDUC, é possível atestar que os valores estimados excedem em mais de três vezes o montante efetivamente gasto com novos termos de contratos realizados especificamente para garantir o novo modelo. Nesse sentido, cabe questionar quais os interesses e motivações de tantas empresas em oferecer seus serviços gratuitamente à rede pública de educação, em especial em um momento de crise econômica. Destaque para a propaganda massiva e ampla desses produtos antes desconhecidos, ou pouco conhecidos aos professores e estudantes de todas as regiões do estado mais populoso da federação, com respaldo e suporte do poder público. A SEDUC, inclusive, faz questão de anunciar essas marcas em uma aba específica em seu principal site de veiculação de informações sobre o ensino remoto.

O significado do caráter donativo carrega em si a ideia de que não haveria qualquer vantagem para os doadores, ameniza o caráter da relação mercadológica e dos interesses econômicos envolvidos e camufla os benefícios desses contratos para essas empresas. As vantagens para a iniciativa privada advindas dessas "doações" podem ser confirmadas pelo fato de que metade das plataformas educacionais discriminadas na Tabela 2 (Descomplica, Letrus, Stoodi, Explicaê, Joca, Mangahigh.com) firmaram termo aditivo de seus produtos, com prorrogação de prazo e aumento expressivo dos valores estimados doados. O exemplo da plataforma Mangahigh.com, gerida pela empresa Blue Duck Educação do Brasil Ltda., é bem elucidativo sobre isso: o termo de doação inicial celebrado em 05 de maio de 2020 estava estimado em $\mathrm{R} \$ 1,38$ milhão, em valores corrigidos, e valia por 60 dias; já o termo aditivo assinado em 05 de julho de 2020 prorrogou a doação de licenças para uso do produto até 31 de dezembro de 2021 e ampliou seu alcance, fazendo saltar o valor estimado para $R \$ 67,02$ milhões igualmente corrigidos. No caso da editora responsável pela plataforma Acerta Mais ENEM, houve a celebração de mais um novo contrato, envolvendo oferecimento de conteúdo de aulas preparatórias para o ENEM. As empresas IP.TV e Pic Pay também prorrogaram contratos, aumentando o valor "doado" - ou, seria melhor dizer, investido.

Esse processo tem sido denominado de "nova filantropia" por Ball e Olmedo (2013), quando há uma diluição das fronteiras entre uma ação social, com sentido de generosidade e desprendimento, e atitudes comerciais, financeiras e empresariais que envolvem a busca por metas e índices corporativos. Para esses autores,

O que há de 'novo' na 'nova filantropia' é a relação direta entre a caridade e os 'resultados' e o envolvimento direto dos doadores nas ações filantrópicas e nas comunidades de políticas. [...] Os 'novos' filantropos querem ver impactos claros e mensuráveis e resultados de seus 'investimentos' de tempo e dinheiro (BALL; OLMEDO, 2013, p. 33-34).

9 Dados obtidos via Sistema de Informação ao Cidadão (SIC), por meio do protocolo n 589802016557 no site da Secretaria da Educação do Estado de São Paulo em 10 set. 2020. 
Um atributo importante dessa nova dinâmica é justamente a evocação de "receitas mágicas" ou "soluções genéricas e escaláveis" (BALL; OLMEDO, 2013, p. 38, grifos dos autores), que passam a interferir com força nas políticas públicas, diante de grandes problemas sociais - a exemplo de como o ensino remoto tem sido exposto atualmente.

Avelar (2020) relaciona as "soluções tecnológicas" - oferecidas como um atalho para a superação dos desafios da educação em meio à pandemia - com o fortalecimento dessa "nova filantropia".

Esta nova filantropia advém do mundo corporativo, do investimento de risco e das empresas de tecnologia (em especial da cultura do Vale do Silício). Por isso, estas organizações importam lógicas corporativas, como foco em resultados mensuráveis, trabalho em larga escala. Na busca de formas de 'alavancar' seus investimentos limitados e gerar 'maior impacto', estas organizações veem a participação na política pública como uma forma 'eficiente' de alcançar 'impacto' (AVELAR, 2020).

Durante o ensino remoto, por diversas vezes houve palestras voltadas para professores com o Instituto Ayrton Senna, com a Microsoft e formações dedicadas a explorar as funcionalidades de plataformas educacionais privadas específicas. Esses eventos ou cursos ocorriam via CMSP, inclusive alguns deles em horários de planejamento e ATPC, que são obrigatórios dentro da carga horária docente. A própria SEDUC também organizou tutoriais para utilização dos novos produtos e divulgou palestras ministradas por essas empresas, institutos e fundações através do e-mail institucional.

\section{Considerações Finais}

As políticas educacionais do estado de São Paulo durante a pandemia tiveram seu foco voltado para garantir que as "oportunidades" de negócios fossem aproveitadas ao máximo. Em sintonia com a tendência de privatização que avançava sobre a rede desde a década de 1990, um dos verdadeiros legados do modelo de ensino remoto será o aprofundamento e a complexificação das formas de privatização da educação básica no estado.

Durante o período da quarentena, os investimentos e esforços do estado de São Paulo não foram direcionados para fortalecer o espaço público da escola na perspectiva de longo prazo. O sentido do ensino remoto foi contaminado pela lógica gerencialista empresarial e não teve como prioridade o fortalecimento do vínculo de nossas crianças e jovens com a escola, nem a construção do ambiente escolar como um ponto de apoio para a comunidade diante da maior pandemia dos últimos 100 anos.

As tão proclamadas "reinvenção" e "inovação" do momento não se propuseram nem mesmo a expandir o acesso público à internet na maior rede de ensino do País, mas, isto sim, promoveram um completo ofuscamento dos grandes dilemas que a educação pública enfrenta há anos no estado - tais como salas de aula superlotadas, professores mal remunerados e desvalorizados, falta de funcionários, falta de materiais básicos, problemas nas instalações físicas, falta de bibliotecas, laboratórios, computadores e demais equipamentos tecnológicos etc.

Os verdadeiros "parceiros" da SEDUC não foram seus professores, funcionários, pais e estudantes, isto é, a comunidade escolar, mas, sim, setores empresariais que veem na educação básica uma grande chance de negócio por meio das políticas educacionais e, assim, aumentar suas margens de lucro e acumulação. 
A REE-SP foi tomada por um grande "feirão de produtos e serviços", levando a patamares exorbitantes a tendência privatista já em curso nas escolas estaduais paulistas e se consolidando como um laboratório para experimentação de articulações ambiciosas entre o poder público e entes privados vinculados ao negócio educacional e às tecnologias digitais - ironicamente apresentados com a roupagem da "filantropia" e das "doações". Os "novos filantropos" adentram a "janela de oportunidades" gerada no momento da pandemia: deixam de pagar impostos, legitimados pelo Estado, e adquirem uma propaganda massiva para seus negócios. A doação se apresenta como um novo eufemismo para privatização. Na realidade, é o poder público quem está prestando um grande serviço de divulgação, propaganda e isenção de impostos a uma gama de empresários.

A sutileza desses agentes junto à SEDUC contribuiu para moldar a política educacional no período e estes contarão com maior abertura para orientá-las no futuro. As relações preferenciais do governo estadual paulista acentuaram as amarras da escola pública com setores que tratam a educação enquanto um serviço, logo, uma mercadoria, e não mais um direito fundamental de acordo com os princípios constitucionais que o regem. Descaracterizase, assim, a educação enquanto direito de todos e dever do Estado e esvai-se, simultaneamente, a função social da escola.

\section{Referências}

ADRIÃO, Theresa; GARCIA Teise. Subsídio público ao setor privado: reflexões sobre a gestão da escola pública no Brasil. Políticas Educativas, Porto Alegre, v. 7, n. 2, p. 110-122, 2014.

ADRIÃO, Theresa; GARCIA, Teise; DRABACH, Nadia. A influência de atores privados na educação paulista: a primeira geração da privatização. Políticas Educativas, Curitiba, v. 13, n. 2, p. 96-108, 2020. Disponível em: https://www.seer.ufrgs.br/Poled/article/view/107517. Acesso em: 20 dez. 2020.

AVELAR, Marina. Educação e COVID-19: cenário para o avanço da privatização? Campanha Nacional pelo Direito à Educação, 04 jun. 2020. Disponibilidade em: https://campanha. org.br/analises/marina-avelar/educacao-e-covid-19-cenario-para-o-avanco-da-privatizacao/. Acesso em: 19 set. 2020.

BAHEMA EDUCAÇÃO S.A. Site oficial. 2020. Disponível em: https://www.bahema.com.br/acompanhia/historia/. Acesso em: 20 set. 2020.

BALL, Stephen; OLMEDO, Antonio. A 'nova' filantropia, o capitalismo social e as redes políticas globais em educação. In: PERONI, Vera (Org.). Redefinições das fronteiras entre o público e o privado: implicações para a democratização da educação. Brasília: Liber Livro, 2013.

BEHAR, Patrícia Alejandra. O Ensino Remoto Emergencial e a Educação a Distância. Jornal da Universidade, Porto Alegre, UFRGS, 2020. Disponibilidade em: https://www.ufrgs.br/coro navirus/base/artigo-o-ensino-remoto-emergencial-e-a-educacao-a-distancia/. Acesso em: 28 set. 2020.

BLANCO, Alessandra; VAZ, Tatiana. Conheça a Bahema Educação, a empresa focada em criar pessoas críticas e autônomas. 31 mar. 2019. Disponível em: https://gq. 
globo.com/Prazeres/noticia/2019/03/conheca-bahema-educacao-empresa-focada-em-criarpessoas-criticas-e-autonomas.html. Acesso em: 20 set. 2020.

BRASIL. Lei n. 10.836, de 9 de janeiro de 2004. Cria o Programa Bolsa Família e dá outras providências. Diário Oficial da União, Brasília-DF, 2004. Disponibilidade em: http://www.mds.gov.br/webarquivos/publicacao/bolsa_familia/Cadernos/Coletanea_Legislaca oBasica.pdf. Acesso em: 10 set. 2020.

BRASIL. Decreto n. 6.135, de 26 de junho de 2007. Dispõe sobre o Cadastro Único para Programas Sociais do Governo Federal e dá outras providências. Diário Oficial da União, Brasília-DF, 2007. Disponibilidade em: http://www.mds.gov.br/webarquivos/publicacao /bolsa_familia/Cadernos/Coletanea_LegislacaoBasica.pdf. Acesso em: 24 set. 2020.

BRASIL. CADE. Aquisição da Estácio pela Kroton é vetada pelo Cade. Brasília: Assessoria de Comunicação Social, 28 jun. 2017. Disponível em: http://www.cade.gov.br/noticias/a quisicao-da-estacio-pela-kroton-e-vetada-pelo-cade. Acesso em: 20 set. 2020.

BRASIL. Decreto n. 6, de 20 de março de 2020. Reconhece, para os fins do art. 65 da Lei Complementar $n^{\circ} 101$, de 4 de maio de 2000 , a ocorrência do estado de calamidade pública, nos termos da solicitação do Presidente da República encaminhada por meio da Mensagem $n^{\circ}$ 93, de 18 de março de 2020. Diário Oficial da União, Brasília-DF, 2020. Disponível em: http://www.planalto.gov.br/ccivil_03/portaria/DLG6-2020.htm. Acesso em: 10 set. 2020.

CARVALHO, Celso do Prado Ferraz de; RUSSO, Miguel Henrique. Neoliberalismo e educação no Brasil: a política educacional do estado de São Paulo. Revista Latinoamericana de Políticas y Administración de la Educación, Ano I, n. 1, p. 94-104, set. 2014.

CÁSSIO, F.; AVELAR, M.; TRAVITZIKI, R.; NOVAES, T. A. F.; Heterarquização do Estado e a expansão das fronteiras da privatização da educação em São Paulo. Educação \& Sociedade, Campinas, p. 1-20, 2020. Disponível em: https://www.scielo.br/j/es/a/kxDYrrv3s TJVFWThpTHZ7vc/?lang=pt. Acesso em: 20 dez. 2020.

CATINI, Carolina R. Privatização e gestão da barbárie - crítica da forma do direito. São Paulo: Edições Lado Esquerdo, 2018.

FEPESP. Federação dos Professores do Estado de São Paulo. Kroton: gigante se reorganiza, de olho na Educação Básica. 08 out. 2019. Disponível em: http://fepesp. org.br/noticia/kroton-gigante-se-reorganiza-de-olho-na-educacao-basica/. Acesso em: 20 set. 2020 .

FERNANDES, Maria José; BARBOSA, Andreza; VENCO, Selma. O trabalho docente na rede pública de ensino do estado de São Paulo-Brasil no contexto da Nova Gestão Pública. Revista Educación, Política y Sociedad, Madri, v. 4, n. 1, jan./jun. 2019. Disponível em: https://revistas.uam.es/reps/article/view/12308. Acesso em: 15 set. 2020.

FINEDUCA. Não é hora de retroceder no Fundeb. Nota Técnica. 20 jul. 2020. Disponível em: https://fineduca.org.br/wp-content/uploads/2020/07/Fineduca_Nota_20200720.pdf. Acesso em: 01 ago. 2020.

FREITAS, Luis Carlos. A reforma empresarial da educação: velha direita, novas ideias. São Paulo: Expressão Popular, 2018. 
GALZERANO, Luciana Sardenha. Grupos empresariais e a educação básica: estudo sobre a Somos Educação. 2016. Dissertação (Mestrado em Educação) - Universidade Estadual de Campinas, Campinas, 2016.

GIROTTO, Eduardo D.; JACOMINI, Márcia A. Entre o discurso da excelência e a lógica do controle: os riscos do Programa Ensino Integral na rede estadual de São Paulo. Revista de Ciências da Educação, Americana, ano XXI, n. 45, p. 87-113, jul./dez. 2019. Disponível em: http://revista.unisal.br/ojs/index.php/educacao/article/view/822. Acesso em: 20 dez. 2020.

GOULART, Débora; PINTO, José Marcelino Rezende; CAMARGO, Rubens Barbosa de. Duas reorganizações (1995 - 2015): do esvaziamento da rede estadual paulista à ocupação das escolas. ETD - Educação Temática Digital, Campinas, v. 19, n. 1, p. 109-133, jan./mar. 2017.

GOULART, Débora; ALENCAR, Felipe. Inova Educação na rede estadual paulista: programa empresarial para formação do novo trabalhador. Germinal: Marxismo e Educação em debate, v. 13, n. 1, p. 337-367, 2021. Disponível em: https://periodicos.ufba.br/index.php/ revistagerminal/article/view/43759. Acesso em: 28 maio 2021.

KROTON fecha compra da Somos Educação por R\$ 4,6 bilhões. G1, globo.com, Economia, 23 abr. 2018. Disponível em: https://g1.globo.com/economia/noticia/kroton-fecha-compra-dasomos-educacao-por-r-46-bilhoes.ghtml. Acesso em: 20 set. 2020.

LDE. Laboratório de Dados Educacionais. Curitiba: Universidade Federal do Paraná, 2020. Disponível em: https://dadoseducacionais.c3sl.ufpr.br/\#/. Acesso em: 19 ago. 2020.

MANGAHIGH WESTERMANN. Site oficial. 2020. Disponível em: https://www. mangahigh.com/pt-br/. Acesso em: 20 set. 2020.

PALHARES, Isabela. SP e GO usam inteligência artificial para motivar alunos e evitar evasão escolar. Folha de São Paulo, São Paulo, 13 ago. 2020. Disponível em: https://www1.folha.uol.com.br/educacao/2020/08/sp-e-go-usam-inteligencia-artificial-paramotivar-alunos-e-evitar-evasao-escolar.shtml. Acesso em: 09 set. 2020.

SAMOR, Geraldo. Somos compra a Stoodi, 'edtech' de reforço escolar. Brazil Journal, 08 dez. 2017. Disponível em: https://braziljournal.com/somos-compra-a-stoodi-edtech-dereforco-escolar. Acesso em: 20 set. 2020.

SÃO PAULO. Secretaria da Educação. Parceria inédita da Educação com o Google amplia programa de tecnologia da rede. 27 nov. 2013. Disponível em: https://www.educacao. sp.gov.br/parceria-inedita-da-educacao-com-o-google-beneficia-rede-estadual-de-ensino/. Acesso em: 02 ago. 2021.

SÃO PAULO. Secretaria de Educação. GOOGLE. Proposta de parceria e transformação. Minuta das condições do convênio. São Paulo, 28 de janeiro de 2014.

SÃO PAULO. Decreto n. 64.879, de 20 de março de 2020. Reconhece o estado de calamidade pública, decorrente da pandemia de COVID-19, que atinge o Estado de São Paulo, e dá providências correlatas. Diário Oficial do Estado de São Paulo, São Paulo, 2020a. Disponível em: https://www.al.sp.gov.br/repositorio/legislacao/decreto/2020/decreto-6487920.03.2020.html. Acesso em: 10 set. 2020. 
SÃO PAULO. Portal do governo. Governador sanciona nova previdência de SP. 06 mar. 2020b. Disponível em: https://www.saopaulo.sp.gov.br/spnoticias/governador-sanciona-novaprevidencia-de-sp/\#: :text=A\%20reforma\%20prev\%C3\%AA\%20respeito\%20ao,policiais\%20 e\%20pessoas\%20com\%20defici\%C3\%AAncia. Acesso em: 15 set. 2020.

SÃO PAULO. Secretaria da Educação. Centro de Mídias da Educação de São Paulo. Site oficial. São Paulo, 2020c. Disponível em: https://centrodemidiasp.educacao.sp.gov.br/. Acesso em: 14 out. 2020.

SÃO PAULO. Secretaria da Educação. Escola Mais disponibiliza plataforma de estudos para alunos e professores da rede estadual. 17 set. 2020d. Disponível em: https://www.educacao.sp.gov.br/noticias/escola-mais-disponibiliza-plataforma-de-estudospara-alunos-e-professores-da-rede-estadual/. Acesso em: 20 set. 2020.

SÃO PAULO. Secretaria de Educação. Resolução 27 SE, de 18 de março de 2020. Diário Oficial do Estado de São Paulo, São Paulo, 2020e. Disponível em: http://www.educacao. sp.gov.br/lise/sislegis/detresol.asp?strAto=202003180027. Acesso em 20 set. 2020.

SÃO PAULO. Secretaria da Educação. SEDUC Informa, São Paulo, n. 3, 17 de mar. $2020 f$. Disponível em: https://deregistro.educacao.sp.gov.br/coronavirus-seduc-informa/. Acesso em: 10 set. 2020.

SÃO PAULO. Secretaria da Educação. SEDUC Informa, São Paulo, n. 10, 3 abr. 2020g. Disponível em: https://deitu.educacao.sp.gov.br/06-04-2020-seduc-informa-novocoronavirus-no-10/. Acesso em: 10 set. 2020.

SÃO PAULO. Secretaria da Fazenda e Planejamento. Doações de combate ao coronavírus - como contribuir sem incidência de impostos. São Paulo, 2020h. Disponível em: https://www.saopaulo.sp.gov.br/coronavirus/doacoes/. Acesso em: 15 set. 2020.

SÃO PAULO. Transparência SP. São Paulo, 2020i. Disponível em: https://www.saopaulo. sp.gov.br/coronavirus/transparencia/. Acesso em: 15 set. 2020.

SEKI, Allan Kenji. Determinações do capital financeiro no Ensino Superior: fundo público, regulamentações e formação de oligopólios no Brasil (1990-2018). 2020. Tese (Doutorado em Educação) - Universidade Federal de Santa Catarina, Florianópolis, 2020.

SOUZA, Artur Gomes de; EVANGELISTA, Olinda. Pandemia! Janela de oportunidades para o capital educador. Contrapoder, 15 abr. 2020. Disponível em: https://contrapoder.net /colunas/pandemia-janela-de-oportunidade-para-o-capital-educador/. Acesso em: 12 out. 2020.

STOODI Ensino e Treinamento à Distância SA. Site oficial. 2020. Disponível em: https://www.stoodi.com.br/quem-somos/. Acesso em: set. 2020.

UNESCO. Guidance on Open Educational Practices during COVID-19 pandemic. 26 maio 2020. Disponível em: https://nacoesunidas.org/unesco-lanca-publicacao-com-orientacoessobre-praticas-educacionais-abertas-durante-a-pandemia/. Acesso em: 31 ago. 2020.

VARGAS, Ivan Martínez. Lemann dará maior ênfase a ensino virtual em suas fundações. Folha de São Paulo, São Paulo, 13 maio 2020. Disponível em: https://www1. 
Pandemia

folha.uol.com.br/mercado/2020/05/lemann-dara-maior-enfase-a-ensino-virtual-em-suasfundacoes.shtml. Acesso em: 31 ago. 2020.

VENCO, Selma. Precariedades: desdobramentos da Nova Gestão Pública no trabalho docente. Crítica e Sociedade - Revista de Cultura Política, Uberlândia, v. 6, n. 1, nov. 2016a.

VENCO, Selma. Terceirização nos tempos do cólera: o amor do setor público à precariedade. Argumentos Pró-Educação - Revista de Educação da UNIVÁS, Pouso Alegre, v. 1, n. 3, set./dez. 2016b.

WESTERMANN GRUPPE. Westermann Gruppe acquires Blue Duck Education the company behind Mangahighcom. 2020. Disponível em: https://www.westermanngruppe. de/en/detailed-view/westermann-gruppe-acquires-blue-duck-education-the-company-behindmangahighcom/. Acesso em: 20 set. 2020.

Carolina Barbosa Gomes Figueiredo Filho é licenciada e bacharel em Ciências Sociais (2009) e Mestra em Ciência Política pela Universidade Estadual de Campinas (2013). Doutoranda em Educação pela Universidade Estadual de Campinas, pesquisa o processo de privatização na educação básica e a precarização do trabalho docente no estado de São Paulo. Atua como professora de educação básica na rede estadual de ensino de São Paulo. ORCID: http://orcid.org/0000-0002-0849-7416

E-mail: carolinafilho@gmail.com

João Batista Silva dos Santos é licenciado em Física pela Universidade de São Paulo (USP), Mestre em Educação pela Universidade Federal de São Paulo (UNIFESP), na linha de pesquisa em Políticas Educacionais. Professor de Educação Básica da rede estadual de ensino de São Paulo.

ORCID: http://orcid.org/0000-0002-1027-7252

E-mail: santos.jbatista@gmail.com 